\title{
A OPC̣ÃO PELO MAGISTÉRIO REPRESENTADA POR PROFESSORAS DE ENSINO FUNDAMENTAL EM MEMORIAIS'
}

\author{
Lúcia Velloso Maurício*
}

RESUMO: Este trabalho procurou elucidar a constituição de representações sociais por meio da memória social. Foram analisados 31 memoriais de professoras de $1^{\mathrm{a}}$ a $4^{\mathrm{a}}$ série como trabalho final em curso de atualização. Memórias pessoais têm como objeto a história de vida de cada um, mas são sociais pelo seu conteúdo. As professoras se distribuíram equitativamente entre efetivas e contratadas, com largo leque etário. As categorias emergiram dos memoriais por meio da análise de conteúdo. Os resultados apontaram maior coesão nos relatos das professoras concursadas e perceptível preocupação com a renovação de contrato pelas não-efetivas. Em vez de representação social sobre o fazer docente, os depoimentos estavam ancorados na representação de aluno, responsável pelos obstáculos que se impõem à prática docente. Predominou a valorização do aprendizado prático: aprende-se trabalhando. Os memoriais indicaram que a opção pelo magistério se dá pela vocação, pela instituição formadora e pelas experiências iniciais de trabalho.

Palavras-chave: Representação e Memória Social; Formação de Professores; Opção pelo Magistério

\section{THE OPTION FOR TEACHERSHIP REPRESENTED BY PRIMARY EDUCATION TEACHERS IN ACADEMIC MEMORIALS}

ABSTRACT: Assessment of the frame of social representations through the social memory of primary education teachers. Thirty-one academic memorials written by first to fourth grade teachers as a final work for an updating course were analyzed. Personal reminiscences describe private lives, but they are social recollections in their very content. Teachers were equally grouped in permanent and contracted, largely varying in age, and these categories were assessed by means of content analysis. The results pointed to a greater cohesion in the public teachers' reports, while contracted teachers were perceptively worried about contract renovation. Instead of showing the social representation of the teaching activities, the reports were attached to the students' representation, responsible for the obstacles to the teaching practice. The practical apprenticeship valorization prevailed: one learns by working. The academic memorials pointed that the option for teachership is based on vocational grounds, on the educational institution one has attended, and by one's own first occupational experiences.

Keywords: Social Representation and Social Memory; Teachers' Formation; Option for Teachership

* Doutora em Educação pela Faculdade de Educação da Universidade Federal do Rio de Janeiro (UFRJ); Professora-adjunta do Mestrado em Educação da Universidade Estácio de Sá (UNESA) e Professora-adjunta da Faculdade de Formação de Professores da Universidade do Estado do Rio de Janeiro (UERJ).E-mail: luciavelloso@terra.com.br 


\section{INTRODUÇÃO}

Este trabalho originou-se de um encantamento circunstancial. Em 2004, participei da formulação e do acompanhamento de um curso de atualização de professores promovido pela Secretaria de Educação do Estado do Rio de Janeiro, por meio da Fundação Darcy Ribeiro (FUNDAR). A Fundação foi responsável pelo planejamento do curso, pela preparação do material didático e por selecionar e preparar os dinamizadores e o apoio on-line. O curso, que se destinava a professores da rede pública de Ensino Fundamental e de Ensino Médio, tinha como exigência a produção escrita de memorial como trabalho de conclusão. Desenvolvido em 29 municípios do estado do Rio de Janeiro, o curso agrupou 68 turmas, envolvendo 1403 professores, durante oito encontros mensais. Os certificados foram conferidos aos 1293 profissionais que produziram seus memoriais. O contato com essa produção escrita, que relaciona o exercício do magistério atual à memória de formação dessas professoras, reacendeu antiga curiosidade de investigar a relação entre representação social e memória.

As representações sociais são construídas ao longo do tempo. Elas são alimentadas em várias circunstâncias, simbólicas ou não, e circulam na sociedade, entre as pessoas em geral e nas escolas, no interior do agrupamento social que exerce o magistério. O fato de o magistério ser uma profissão predominantemente feminina, particularmente no Ensino Fundamental, imprime marcas que vêm se modificando ao longo do tempo. O estudo da memória, por meio de histórias de vida, pode contribuir para elucidar a construção de representações sociais no passado. Há autores, como Roussiau; Bonardi (2002), Sá (2005), Jedlowski (2005) e Valencia (2005), empenhados na discussão teórica sobre memória social e representação social. Este trabalho aproveitou a oportunidade de explorar o acervo empírico produzido neste curso para colaborar com o desvelamento das relações entre representação social e memória social.

\section{REPRESENTAC̣ÃO SOCIAL, HISTÓRIA DE VIDA E MEMÓRIA SOCIAL}

Tomamos a representação social como uma forma de conhecimento, um saber prático que se refere exatamente à experiência a partir da qual ele se produz e serve para agir sobre o mundo (JODELET, 1989). Pela relação que estabelece com o imaginário social e por levar à ação, a representação social torna-se essencial para compreender mecanismos 
que interferem no processo educativo, pois as interações sociais vão criando consensos que constituem verdadeiras "teorias" do senso comum (ALVES-MAZZOTTTI, 1994).

Segundo Jodelet (1989), a representação social é sempre representação de alguma coisa e de alguém na qual as características do sujeito e do objeto se manifestam. A representação social simboliza e interpreta o objeto, substituindo-o e atribuindo-lhe sentido. A representação é construção e expressão do sujeito que se dá por meio de processos cognitivos e psíquicos, com a particularidade de incorporar, na análise dos processos, a pertença e a participação social e cultural do sujeito.

A memória é entendida como "uma rede complexa de atividades, cujo estudo mostra que o passado nunca permanece uno e idêntico a si, mas é constantemente selecionado, filtrado e reestruturado por questões e necessidades do presente, tanto no nível individual como no social" (JEDLOWSKI, 2005, p. 87). Compartilhamos a categorização sistematizada por Sá (2005), que utiliza o termo "memória social" para designar o conjunto dos fenômenos ou instâncias sociais da memória. Justifica o adjetivo "social" porque parece ser o mais adequado para abranger o campo da memória na sociedade e também por observar que, de forma espontânea, o termo já vem sendo preferido na literatura sobre memória em sociedade.

Ao definir memórias pessoais, Sá descarta a possibilidade de se referir a memórias que digam respeito ao indivíduo, no sentido que é adotado pela Psicologia Social americana, ou não as incluiria como sendo sociais. Memórias pessoais designam "aqueles atos de recordação que tomam como objeto a história de vida de cada um (...), que se localizam num passado pessoal e a ele se referem" (CONNERTON, 1993 apud SÁ, 2005, p. 73). Para o autor, as memórias pessoais são sociais pela sua construção e pelo seu conteúdo, mas se constituem na pessoa e se referem ao seu passado, mesmo que seus conteúdos sejam fatos sociais, culturais ou históricos de que tenha participado, testemunhado ou ouvido falar. Empiricamente, as memórias pessoais têm sido estudadas como memórias autobiográficas ou como histórias de vida.

Jedlowski (2005, p. 87) define memória coletiva como um "conjunto de representações relativas ao passado que cada grupo produz, institucionaliza, cuida e transmite por meio da interação de seus membros". Distingue de memórias comuns porque estas não dizem respeito a grupos e, sim, a recordações que participantes de uma sociedade partilham com outros pelo fato de terem sido expostos às mesmas 
circunstâncias e mensagens. Neste caso, não há necessariamente interação, as pessoas se lembram de fatos comuns por terem visto na televisão ou terem tido acesso por meio de algum tipo de comunicação social. Outras categorias de memória fazem fronteira com aquelas que nos dizem respeito mais de perto, como, por exemplo, memórias públicas. Este trabalho enfocou, particularmente, memórias pessoais e memórias comuns, que eventualmente configuram-se como memórias coletivas.

Roussiau et Bonardi (2002), em artigo sobre o lugar que a memória social ocupa no campo das representações sociais, afirmam que a relação entre memórias individual e coletiva proposta por Halbwachs permanece referência na medida em que os dois tipos de memória fundamentam-se em enquadramentos sociais. A lembrança individual se apóia nos quadros da memória coletiva e esta permite retorno ao passado, no intuito de conformá-lo ao pensamento que domina a sociedade atual. Para que a imagem de um objeto possa representá-lo, é necessário que ela seja comum a um conjunto de indivíduos, portanto, social. Os autores consideram que o conteúdo de uma representação social - conjunto de normas, valores, crenças, imagens, opiniões, atitudes - é concebido com referências ao passado.

Se é importante adaptar as lembranças às necessidades e aos conhecimentos atuais e se estes são influenciados por pertenças grupais, a memória participa da objetivação e da ancoragem das representações sociais. Para Roussiau e Bonardi, a memória exerce influência sobre o conteúdo da representação; considera-se que os processos que intervêm nas representações integram necessariamente fenômenos de memória; e que estes processos orientam e organizam a constituição de representações por meio da filtragem do conteúdo memorizado.

A pesquisa empírica das memórias comuns das professoras teve por base o memorial acadêmico. Ele foi definido como "uma narrativa autobiográfica da vida intelectual e profissional, escrita em resposta a uma demanda institucional" (PASSEGGI, 2006, p. 205). A autora o desdobra em duas modalidades: o memorial descritivo, que é uma reflexão individual referenciada em edital, e o memorial de formação, que constitui um trabalho de conclusão de curso. Tanto um quanto outro têm caráter público, fazem parte de processo avaliativo e tornam-se documentos institucionais que podem ser consultados. $\mathrm{O}$ memorial de formação, que corresponde aos que foram analisados aqui, conta com a participação de um orientador.

É necessário lembrar que a dimensão (auto)avaliativa do memorial se sobrepõe, como preocupação de formandos e orientadores, à sua 
dimensão (auto)formativa, subjacente ao processo de reflexão, mas que, mesmo oculta, é inseparável do processo narrativo do memorial. Este caráter do memorial deve ser levado em consideração para que o discurso para o outro, característico de processos avaliativos, seja identificado e contextualizado. No caso deste trabalho, a narrativa dirigida ficou evidenciada no discurso das professoras contratadas.

Apesar de a análise dos memoriais não ter adotado referencial teórico relacionado ao magistério a priori, pois nosso objetivo era discutir a relação entre representação social e memória social, não podemos deixar de nos referir a, pelo menos, alguns trabalhos que discutem a formação docente por meio de histórias de vida ou memórias narrativas.

Denice Catani (2006), em texto apresentado no II Congresso Internacional sobre Pesquisa (Auto)biográfica, esclarece o ponto de vista de sua abordagem:

Por enquanto, o reconhecimento óbvio da necessidade de bem formar os professores para garantir o futuro das novas gerações, de bem remunerá-los para criar condições de trabalho: eis o cenário onde tudo parece estar por ser feito. (CATANI, 2006, p. 79)

Lembra que na década de 1980, em pesquisa que buscava responder que saberes seriam mais produtivos para a formação do magistério, constatara grande decepção das candidatas a professoras pelo caráter pouco prático dos conhecimentos que adquiriam. A resposta que hoje dá à sua própria pergunta tem como eixo o que chama de "Cultura da atenção",

Entendida esta como geradora da capacidade de situar-se nas realidades sociais, referir-se às realidades científicas e intelectuais, ancorar-se nas realidades artísticas com a finalidade central de aperfeiçoar-se do ponto de vista humano. (CATANI, 2006, p. 81)

A cultura da atenção visa a dotar o professor dos instrumentos que lhe permitam tornar-se sujeito, de reconhecer-se e reconhecer o outro como sujeito/objeto do conhecimento. Catani considera, apoiada em Certeau, que cultura e comunicação alimentam-se de relatos. E se per-gunta que relatos estamos favorecendo com a educaçào que oferecemos aos professores. Conclui que o aprendizado para a docência deveria fazer parte de um projeto de formação humanística mais enérgico nas relações cognitivas, éticas e estéticas e menos pretensioso nos aspectos didático-pedagógicos. 
Belmira Bueno (2006), referindo-se à revisão de literatura de que participou sobre histórias de vida e autobiografias no Brasil de 1985 a 2003, registra algumas constatações importantes: se, por um lado, a intensificação do uso desta metodologia contribuiu para renovar a pesquisa educacional, particularmente sobre formação de professores; por outro, percebe-se a ausência de interlocução entre estas pesquisas e outras da área; acrescenta a pequena atenção atribuída às reformas educacionais que se desenvolvem na América Latina, inclusive com pouca referência a projetos de formação em países vizinhos submetidos às mesmas políticas internacionais; finalmente, alerta para a imprecisão conceitual em grande parte dos trabalhos, algo que a autora atribui à diversidade de expressões empregadas como se fossem sinônimas ou de sentido consensual e à desconsideração pela história das histórias de vida e pelas diferentes concepções que são utilizadas em diversos campos do conhecimento, redundando em pesquisas com pouco rigor.

Bueno considerou preocupante e interpretou como dispositivo de controle a escrita de memórias proposta pelo PEC-Município, tais a diretividade do Programa em análise e o curto prazo previsto para que os professores adquiram outro perfil. Lembrou que é preciso tempo para incorporar determinados habitus às práticas, e isso tem implicações significativas, no caso dos professores, pois sua ação pedagógica é marcada pela urgência e pela improvisação, que são colocadas pelas precárias condições de trabalho. A intuição que orienta suas práticas mobiliza saberes que se consolidam por meio do habitus. A autora enfatiza que a formação do professor começa antes de sua entrada nos cursos de magistério, pois imagens e representações estão enraizadas em experiências da infância ou na convivência com indivíduos da própria escola.

Apesar dessas considerações, Bueno reconheceu que a escrita de memórias proposta pelo Programa desempenhou papel importante entre as práticas que favorecem ao professor reinventar a si mesmo, pois auxiliam-nos a perceber

Os fatores que entram em jogo na produção da vida escolar, da qual eles tomam parte ativa. Pois, é nesse plano que a profissão docente ganha sentido para eles, é nesse contexto que eles podem subverter normas e modelos que não lhes fazem sentido, reinventando a si mesmos e a própria escola, mesmo que parcialmente. (BUENO, 2006, p. 232) 


\section{PROCEDIMENTOS METODOLÓGICOS}

Neste trabalho, analisamos 31 memoriais entre os 94 apresentados pelos professores de $1^{\mathrm{a}}$ a $4^{\mathrm{a}}$ série do município de São Gonçalo. Nosso objetivo era pesquisar a relação entre a representação social do fazer docente e a memória social sobre a opção pelo magistério expressa por meio da memória pessoal das professoras e registrada em seus memoriais. O município de São Gonçalo foi selecionado por suas condições socioeconômicas de periferia do Grande Rio; por ter alcançado o maior número de memoriais produzidos; e, principalmente, por abrigar faculdade pública de formação de professores, portanto com interesse na produção de conhecimento sobre fazer docente e opção pelo magistério.

Este curso, cuja freqüência era oferecida a qualquer professor da rede estadual, priorizava a matrícula daqueles, estatutários ou contratados, que estivessem lecionando em escolas que funcionavam ou pretendiam funcionar em horário integral. Como, no Estado do Rio de Janeiro, os prédios dos Centros Integrados de Educação Pública (CIEP) foram construídos para essa finalidade, a grande maioria dos professores envolvidos exercia sua atividade docente em CIEP. Esta foi a quarta versão do curso, mas a primeira em que se pedia a elaboração de memorial como trabalho final.

O curso tinha como objetivos: 1) abordar os conteúdos de Ensino Fundamental e Médio e suas metodologias, de acordo com as diretrizes para formação de professores de educação básica, colaborando para que os professores pudessem superar a atuação fragmentada e superficial; 2) estimular a releitura do contexto escolar, de forma a evitar que prevaleçam, entre os professores, visões preconceituosas a respeito do aluno da escola pública que se origina dos segmentos mais pobres da população; 3) oferecer recursos de ensino à distância para permitir ao professor-cursista superar restrições de ordem temporal. O memorial foi tomado como um depoimento escrito sobre o processo vivido ao longo do curso que articulasse teoria e prática à reflexão sobre sua prática pedagógica. A proposta de memorial tinha por base a concepção de que ele relata um processo individual, que reúne história pessoal e profissional, registrando acertos e erros no processo de construção da prática pedagógica².

O material analisado incluía uma ficha de caracterização socioeconômica do professor-cursista e o memorial produzido. $\mathrm{O}$ preenchimento integral da ficha foi critério de seleção dos 31 entre os 94 me- 
moriais produzidos por professoras de $1^{\mathrm{a}}$ a $4^{\mathrm{a}}$ série no município de São Gonçalo. Esses dados foram tabulados de forma a construir um perfil do professor e para verificar as relações possíveis entre os dados de inserção social, como será descrito na análise dos resultados. Da ficha constavam informações como idade, vínculo funcional, tempo de magistério, tempo de formação, escola em que trabalha, entre outras.

Como já mencionamos, não adotamos, de antemão, categorias da literatura especializada em formação docente. Os parâmetros de análise foram emanando da leitura dos memoriais, centrados nas temáticas opção pela docência e fazer docente, trabalhados na perspectiva de análise de conteúdo de Bardin (2000). Ensaiamos 22 aproximações, algumas mais vinculadas à opção por ser professor e outras mais relacionadas à prática de sala de aula. Claro está que essas aproximações se interpenetram, como não poderia deixar de ser, afinal o fazer docente tem muitas raízes plantadas na opção pelo magistério.

Dentro da vertente "opção pela docência", destacamos vocação/motivação, formação para o magistério, exercício inicial da profissão, gosto pelo estudo e pela leitura, objetivos da educação, papel do professor, outras experiências educativas, concurso público, abandono do magistério e situação socioeconômica do professor como fatores que interferem ou revelam decisões relativas à adoção da profissão. $\mathrm{Na}$ vertente que abrange a prática do magistério, os depoimentos enfatizaram funções dentro da escola, aluno, estratégias para desenvolvimento do aluno, para desenvolvimento do professor, leituras, cursos, faculdade, escola e dificuldades.

Finalmente, ensaiamos relacionar as categorias que predominaram nos memoriais aos traços socioeconômicos que singularizavam tipos de professores participantes. Essas relações, que nos levaram a reconhecer diferença de perfil entre professores efetivos e contratados, permitiram-nos identificar alguns núcleos de memória e verificar como a memória social se compõe de representações sociais.

Antes de passar aos resultados, registramos os limites desta pesquisa, tendo em vista que não adotamos outro instrumento metodológico, além da ficha de caracterização socioeconômica e do memorial. Passeggi et al. (2006, p. 258) sugerem que a narrativa "supostamente cerceadora" seja confrontada com a "fala mais descontraída", por exemplo, por meio de entrevista conversacional, como adotou em seu trabalho. Mesmo assim, afirmam que, dos dados colhidos, não emergiram fatos conflitantes entre os que se originaram dos memoriais e os que foram 
elaborados a partir das entrevistas. Essa percepção levou as autoras a reconhecer o poder de reconfiguração do mundo por meio de narrativas nas duas estratégias utilizadas (PASSEGGI et al., 2006, p. 266). Assim, apesar da abrangência mais restrita, consideramos que os resultados já obtidos configuravam achados significativos que mereciam ser tornados públicos.

\section{ANÁLISE DOS RESULTADOS Os professores envolvidos}

O universo de 31 docentes distribuía-se entre professoras efetivas do estado e professoras contratadas temporariamente. Duas professoras, que na época do curso eram contratadas, foram analisadas dentro do grupo de efetivas: uma porque foi efetiva durante 9 anos e está aguardando ser chamada novamente; outra porque foi professora bolsista no início das atividades dos CIEPs, em 1993. A distinção entre efetivas e contratadas é importante para este trabalho exatamente porque queremos verificar em que medida a memória pessoal das docentes, mesmo que sem uma interação, constitui memória social pela exposição a situações sociais semelhantes, sejam elas diretrizes do estado em geral ou específicas para professores de escola de horário integral, ou mesmo advindas de formação comum por meio dos institutos de educação. Antes de detalharmos os dados objetivos do universo docente, lembramos suas características comuns: todas são professoras do primeiro segmento do Ensino Fundamental e todas têm formação de nível médio. Não foi propositado, mas o grupo é composto apenas por mulheres.

TABELA 1: Sujeitos da pesquisa por idade e relação institucional

\begin{tabular}{c|c|c|c|c|c|c} 
IDADE & EFETIVO & $\%$ & CONTRATO & $\%$ & TOTAL & $\%$ \\
\hline Até 30 anos & 4 & $13 \%$ & 6 & $19 \%$ & 10 & $32 \%$ \\
De 30 a 39 & 8 & $26 \%$ & 1 & $3 \%$ & 9 & $29 \%$ \\
Mais de 40 & 4 & $13 \%$ & 7 & $23 \%$ & 11 & $36 \%$ \\
Não indicado & - & $0 \%$ & 1 & $3 \%$ & 1 & $3 \%$ \\
TOTAL & 16 & $52 \%$ & 15 & $48 \%$ & 31 & $100 \%$
\end{tabular}

Essa tabela evidencia que os sujeitos pesquisados se distribuem equitativamente entre professoras efetivas e contratadas. Num primeiro 
plano, o universo ocupa, de forma homogênea, as três faixas etárias. Mas, se observarmos cada um dos segmentos, veremos que as efetivas predominam na faixa de 30 a 39 anos e as contratadas se dividem entre a faixa mais idosa, acima de 40 anos, e a mais jovem, abaixo de 30. As contratadas não fizeram qualquer referência a concursos para professores públicos.

TABELA 2: Distribuição dos sujeitos por escola e relação institucional

\begin{tabular}{|c|c|c|c|c|c|c|c|c|c|c|c|}
\hline ESCOLA & \multicolumn{8}{|c|}{ CIEP } & \multirow[b]{2}{*}{$\mathrm{Es} / \mathrm{Ji}$} & \multirow[b]{2}{*}{ N.I. } & \multirow[b]{2}{*}{ total } \\
\hline DOCENTE & 041 & 238 & 248 & 249 & 414 & 421 & 423 & 430 & & & \\
\hline Efetivo & 2 & 4 & 1 & 1 & - & - & 1 & 2 & 2 & 3 & 16 \\
\hline Contrato & - & 1 & 4 & - & 1 & 7 & 2 & - & - & - & 15 \\
\hline TOTAL & 2 & 5 & 5 & 1 & 1 & 7 & 3 & 2 & 2 & 3 & 31 \\
\hline
\end{tabular}

A Tabela 2 mostra a distribuição das professoras pelas escolas CIEPs ou outras. A localização dos respondentes indica as situações de interação, que podem repercutir na constituição da memória social. Observam-se três conjuntos de docentes: efetivas no CIEP 238 e contratadas no 248 e no 421. Percebe-se que a lotação das contratadas diverge daquela das efetivas, fato comum no estado, pois as vagas de contrato são localizadas em escolas de difícil acesso. Essa distribuição colabora para isolar um grupo de outro, dificultando a interlocução ente eles, agravando a segmentação do universo em dois grupos.

A Tabela 3 ilustra, mesmo que de forma remota, outra possibilidade de adoção de discurso comum entre as professoras. O curso que elas freqüentaram é a quarta modalidade de preparação de docentes para o exercício do magistério em unidades de tempo integral. Assim, alguns desses sujeitos podem ter constituído representações comuns em anos anteriores, devido a esse possível contato. Assim, relacionamos a seguir o quantitativo de professoras, entre essas 31, que já participaram dos ciclos de estudos anteriores. 
TABELA 3: participação dos sujeitos em ciclos de estudos anteriores, por relação institucional

\begin{tabular}{c|c|c|c|c} 
CICLO & \multicolumn{3}{|c|}{ CICLO DE ESTUDOS } \\
\hline DOCENTE & $\mathbf{2 0 0 1}$ & $\mathbf{2 0 0 2}$ & $\mathbf{2 0 0 3}$ & TOTAL \\
EFETIVO & 4 & 7 & 4 & 15 \\
CONTRATADO & 5 & 3 & 3 & 11 \\
TOTAL & 9 & 10 & 7 & 26 \\
PORCENTAGEM & $35 \%$ & $38 \%$ & $27 \%$ & $100 \%$
\end{tabular}

O Ciclo de Estudos de 2002 envolveu o maior quantitativo de professores porque se desenvolveu dentro de cada unidade escolar. Assim, para a finalidade deste trabalho, deixa de ser significativo, pois os encontros correspondem à interação que ocorre em cada escola e não em grupo formado por meio de pólos. Aqui, temos ilustrada a hipótese de interação entre os dois grupos em 2001 e 2003, apesar da transitoriedade dos contratos. Lembramos que o total 26 não corresponde ao número de pessoas, mas ao número de participações, pois algumas professoras participaram de mais de um ciclo de estudos.

\section{OS MEMORIAIS}

\section{A opção pela docência}

Sobre a opção pela docência, 27 professoras entre as 31, se manifestaram a respeito, seja por vocação inicial ou adquirida posteriormente. Das 17 que afirmaram ter vocação desde a infância, 10 referiram-se a "brincar de escolinha" ou práticas semelhantes e 7, a modelos de professoras que marcaram suas vidas - mãe, tia ou professoras mesmo. As 10 professoras que adotaram o gosto pela profissão no processo de formação indicaram que isso se deu por acaso, no decorrer do curso, por necessidade de trabalhar ou por falta de opção. As profissões que não se efetivaram incluíam pediatria, química, jornalismo e contabilidade. Esses depoimentos não tinham conotação de lamento, como ocorre quando falam de desânimo ou de desvalorização da profissão. São circunstâncias da vida que terminam por consolidar opção tão forte quanto aquela gestada na infância. O depoimento é ilustrativo.

Foi uma turma que acrescentou bastante em minha carreira profissional. Aprendi com eles o melhor caminho, até que descobriram o processo de leitura-escrita. A partir daí concluí "tenho jeito para a coisa. Quero isso para minha vida”. (Estatutária, 34 anos, Est. Adicionais, Ciclos de Estudos 2001, 2002, 2003, memo 9) 
A vocação inicial ou no processo não revelou diferença significativa entre as professoras contratadas e as efetivas. Pode-se dizer que as contratadas indicaram com mais ênfase a vocação desde a infância, portanto as estatutárias tiveram mais forte a vocação adquirida no processo. Essa vocação tardia aparenta mais realismo que a inicial, tendo esta, às vezes, um ranço de frase feita. Não se pode afirmar, a partir dos memoriais, que a vocação inicial revela compromisso mais consistente do que a vocação no processo. Não foi possível perceber relação significativa entre vocação inicial e idade, formação ou vínculo administrativo. A relação mais visível foi entre vocação inicial e gosto pela leitura e pelo estudo: de 10 que declararam este prazer, 7 afirmaram sua vocação pelo magistério desde pequenas.

Sobre a formação para o magistério, 17 professoras vieram de instituições públicas, das quais 15 nomearam seus cursos; 6 indicaram instituições privadas, das quais 5 tiveram seus nomes citados; e 8 não mencionaram sua formação. Nomear a instituição formadora revela que foi uma relação significativa, seja por orgulho ou admiração, seja por crítica ou alguma ressalva. Da mesma forma que não se referir a ela indica, no mínimo, que não deixou marcas visíveis. Para consolidação da vocação, a instituição formadora emergiu como aspecto de destaque. $E$ vai fazer diferença entre as professoras efetivas e as contratadas: das 16 estatutárias, 11 se formaram em instituição pública, 2 em particular e 3 não mencionaram; enquanto das 15 contratadas, apenas 6 estudaram nos institutos de educação ou colégios públicos com formação de professores, $4 \mathrm{em}$ particular e 5 não mencionaram. Essa diferença tanto pode indicar a melhor qualidade dos cursos públicos, permitindo que as normalistas tenham sucesso nos concursos para o magistério, como pode apontar que essas instituições cultivam a vocação, contam com professores que se tornam modelos ou outros elementos consolidadores dessa opção.

O depoimento a seguir ilustra tanto o "clima" formador quanto a possibilidade de diluir uma opção ainda frágil. A professora em questão estudou no Instituto Clélia Nanci, o mais citado entre as instituições públicas do município. De família pobre, não tinha sonho de ser professora. Foi desestimulada, durante o curso, por uma professora de prática de ensino por causa de uma aula aplicada no $2^{\circ}$ ano, segundo seu relato. Não desistiu do magistério para compensar o esforço dos pais e para não se sentir derrotada. Trabalhando com grupos em aula particular, começou a gostar do magistério. Voltou ao Clélia Nanci para fazer estudos adicionais em alfabetização: 
Desta vez, a experiência foi bem mais prazerosa. Encontrei professores excepcionais, os quais considero verdadeiros mestres, pois trabalham de forma apaixonante e contagiante. Foram grandes auxiliares na minha carreira profissional. (Estatutária, 34 anos, Est. Adicionais, Ciclos de Estudos 2001, 2002, 2003, memo 9)

Outro fator que se mostrou significativo para a opção pelo magistério foi a primeira experiência de trabalho. Dos 31 memoriais, apenas 2 não se referiram a essa circunstância. Vemos aqui o inesperado papel da escola particular: por mais que seja admirada ou criticada nos seus aspectos materiais ou didáticos, por mais que seja avaliada negativamente nas relações de trabalho que estabelece, ela funciona como uma espécie de estágio remunerado. Ali a recém-normalista expõe suas fragilidades e ganha força (ou desiste) para enfrentar o mercado de trabalho ou o concurso público.

Trabalhei 5 anos em escola particular fundo de quintal, sem carteira assinada e salário abaixo do legal. Mas a experiência adquirida foi importante para a profissão. Tinha pessoas disponíveis para ajudar, sem tirar liberdade e pude praticar o que aprendi. (Estatutária, 34 anos, N. médio, Ciclo de Estudo 2002, memo 7)

Entre as professoras, 18 se referiram ao trabalho inicial em escola particular e 10 em escola pública, sendo 6 em CIEP. A distinção entre os grupos de professoras não se mostrou no trabalho inicial em escola particular: 9 efetivas e 9 contratadas. Revelou-se, sim, no tipo de escola pública: 5 estatutárias iniciaram sua vida profissional em CIEP e 4 contratadas, em escola pública comum.

Supõe-se que essa diferença decorra da participação no Curso de Atualização de Professores de Escolas de Horário Integral que envolveu cerca de 6500 normalistas recém-formadas no estado do Rio de Janeiro, em 1992 e 1993². Foi uma experiência tão marcante que, das 4 estatutárias pesquisadas participantes daquele curso, três aprofundaram seus compromissos com educação, desempenhando funções de direção ou coordenação. Os depoimentos a seguir mostram a força dessa memória constituída em espaços unitários diferenciados, mas submetidas todas à mesma concepção de educação, de prática pedagógica e de proposta de trabalho:

Pude ajudar na organização de todos os setores da escola... foi uma das melhores experiências que vivenciei. Trabalhei com as bolsistas da mesma forma que me dedico aos meus alunos. (Estatutária, 44 anos, N. médio, Ciclos de Estudo 2001, 2002, 2003, memo 2). 
Tenho muita saudade daquele primeiro ano em 1993, tudo funcionava, tudo era novo, nossos olhos brilhavam pelo encanto de participar de um programa de alto nível, chamado CIEP... No final do ano de 1993, entendi que era verdadeiramente o que eu queria e fiz a prova para o estado, passei e optei em retornar para o mesmo CIEP. (Estatutária, 29 anos, N. médio, Ciclos de Estudo 2001, 2002, 2003, memo 4).

Pude observar, desde o início, a construção do CIEP, que, naquela época, foi considerada escola de primeiro mundo. Foi um dos anos mais felizes da minha vida. Nós, professores bolsistas, éramos capacitados continuamente e muito bem-remunerados. (Estatutária, 30 anos, Est. Adicionais, Ciclos de Estudos 2001 e 2002, memo 5).

Sobre objetivos da educação, dos 31 memoriais, 14 abordaram a temática, indicando que mais da metade desses professores não vivenciam sua prática profissional com a dimensão clara da sua responsabilidade social. Entre os 14 depoimentos, 8 eram de efetivos - metade - e 6, de contratados - menos que a metade. As estatutárias se mostraram mais envolvidas com o compromisso social da educação, seja pela preocupação com a desigualdade social - 4 alegações em 6 - seja pela formação do aluno crítico, só apontado por elas. Nas esparsas observações das contratadas, apareceu o discurso religioso, como se pode notar:

Porque, nesta grande missão com crianças, jovens e adultos, aprendemos a cada dia uma nova lição, que é preciso vencer as dificuldades e instabilidades com fé em prol da realização. Obrigado meu Deus. (Contratada, 49 anos, N. médio, Ciclo de Estudos 2001, memo 24)

A respeito da profissão professor, menos da metade dos memoriais registrou alguma consideração: foram 13 dos 31. Praticamente, não há distinção aqui, quantitativa, entre as professoras estatutárias ou contratadas. Pode-se perceber alguma diferença de conteúdo: as funcionárias públicas, mais voltadas para a função que deveria ser exercida e pela situação de desvalorização do magistério; e as contratadas, ainda afirmando seu orgulho pelo magistério. As críticas, tanto de estatutárias quanto de contratadas, incidiram na descrença do professor e no seu desinteresse ou no pouco empenho. As indicações apontadas pelas estatutárias envolveram a disponibilidade para aprender, a consciência do papel social e a conexão com o tempo da sociedade.

Os desabafos sobre o abandono, ou quase, da profissão, por mais que fossem minoritários (7 em 31), são reveladores da adesão ou da rejeição à função do magistério. Desses depoimentos, sendo apenas um de 
professora contratada, 5 foram realmente consumados, ou seja, houve interrupção do exercício profissional. Essas narrativas evidenciam os limites da vocação: o que é insuportável e o que é mais forte que o insuportável, capaz de fazer o profissional retomar seu exercício. O motivo do abandono, com variações de circunstâncias, é a realidade difícil dos alunos - indisciplina e dificuldade de aprendizagem - no contexto de escola pública brasileira - turmas numerosas, grandes diferenças etárias e falta de recursos. O agravante é que as recém-professoras descobrem a diferença entre a teoria que aprenderam em seus cursos e a realidade que vivenciam na escola pública, em sala de aula, e se sentem desamparadas. Duas professoras mencionaram, descoberta feita anos mais tarde, a composição de suas turmas: alunos que são rejeitados por todos. O que se percebe no retorno à atividade é, digamos, a segunda chance, uma nova oportunidade em circunstâncias em que se encontra algum apoio: uma colega que ajuda, um curso em que se compartilhe a dificuldade, a percepção de que há soluções a partir da experiência com os alunos. Segue um depoimento exemplar tanto da dificuldade quanto da reassunção da atividade:

Como eu era a mais nova professora do colégio e quem entra por último escolhe por último, a turma "montada" com os alunos mais difíceis e com mais dificuldade foi o que coube para mim. Eles tinham um único objetivo: brincar, bagunçar e aprontar. Naquele ano, eu decidi que nunca mais entraria em sala de aula. Lamentando os anos de estudo, estágios, passagens, livros, trabalhos. Ao mesmo tempo, aliviada, pois estava livre das pressões, dos cadernos, planos de aula e, principalmente, da indisciplina dos alunos. O magistério havia ficado para trás. Ficaram apenas as lembranças, que, naquela época, eu não achava nada boas... Minha filha mais velha já estava na idade de ir para a escola. $\mathrm{Na}$ cidade, só uma escola pública tinha jardim de infância e a escola particular, que também só tinha uma, eu não podia pagar. A solução veio do meu marido. Vamos montar um jardim de infância. A princípio eu não fiquei muito animada, eu ia me lembrando das experiências passadas. Porém, conforme eu ia preparando, arrumando, pegando os materiais, os livros, eu ia voltando a ser professora novamente. Voltando a pensar como professora e a agir como professora. A escola começou e eu fui me apaixonando a cada ano que passava. Fui aprendendo, estudando e desejando mais e mais me integrar à escola novamente. Eu estava tão motivada que prestei concurso para o estado. Estudei muito, pois já estava longe dos livros didáticos há muito tempo... me debrucei nos livros com tamanha sede que consegui passar com uma boa classificação. Terminei com a escola. Descobri que administrar é a pior coisa na vida escolar. Hoje voltei para a sala de aula. Trabalho em um CIEP e estou muito motivada. (Estatutária, 37 anos, N. médio, memo 6) 


\section{FAZER DOCENTE}

A escola deveria estar no centro do fazer pedagógico. Mas não foi o que vimos registrado nos memoriais: 13 das 31 professoras se referiram a ela, sem distinção significativa entre efetivas e contratadas. $\mathrm{O}$ foco principal foi a crítica à escola privada: falta carteira assinada; falta liberdade; professor não planeja, só executa; e ensino vira mercadoria. A crítica à escola pública tanto apontou para a segregação dos alunos indesejáveis, aspecto já mencionado antes, quanto para a falta de apoio pedagógico e de compromisso. A crítica à escola em geral é que ela se isola dos outros agentes educativos da sociedade e que é marcada pela desigualdade. Deve cumprir a função de integrar o aluno na sociedade e o meio pelo qual pode atingir essa meta é sendo prazerosa. Dentro dessa moldura, pode-se visualizar o que cabe fazer ao docente: promover a interação dos alunos com outras instâncias educativas da sociedade, visando a minorar a desigualdade, integrando-o e oferecendo atividades que lhe proporcionem prazer.

$\mathrm{E}$ as escolas em que trabalham - os CIEPs - beneficiam ou dificultam a prática docente? Das 31 professoras, 28 trabalham atualmente em CIEP, 2 já trabalharam e apenas uma não tem e não teve contato com esse tipo de escola. Apenas 11 depoimentos a respeito: 10 de estatutárias e um de contratada. Isso parece indicar que, para as contratadas, o CIEP não tem especificidade, é uma escola. E, para as efetivas, ele parece ser mais presente que uma escola qualquer: foram 8 depoimentos sobre escola e 10 sobre CIEP. Dos 11 depoimentos, 6 referiram-se ao projeto inicial de escola de horário integral: $3 \mathrm{com}$ admiração, uma com decepção e 2 apontando possibilidades. As professoras que lembraram com saudade o projeto inicial já foram citadas quando falamos do curso de formação para professores de escola de horário integral. Um dos depoimentos que levanta as possibilidades dentro de um CIEP toca em aspecto central do projeto:

Tive um choque com CIEP: salas lotadas, alunos sem limites, carentes de tudo... precisavam de auxílio tanto quanto eu... não agiria com eles com a repressão... Em 1992, optei por trabalhar 40 horas, comecei então a ter mais tempo para os alunos, o que facilitou nosso relacionamento. (Estatutária, 44 anos, N. médio, Ciclos de Estudo 2001, 2002, 2003, memo 2)

Os outros 5 depoimentos referiram-se mais aos alunos dos CIEPs do que à própria escola; essa aparecia referida na quantidade de alunos em sala ou na variação da idade. Indispensável é apresentar o relato 
de uma professora que se decepcionou a tal ponto com a execução do projeto dos CIEPs que chegou a abandonar o magistério:

Prestei novo concurso em 93 para trabalhar exclusivamente em CIEP com carga horária de $40 \mathrm{~h}$ semanais. Passei na prova e fiquei muito feliz, pois era tudo o que eu queria. Começou o período de planejamento e foi aí que começou a minha decepção. Nesse período, fui descobrindo que o meu trabalho seria estar com as crianças 8 horas diárias em sala de aula, com intervalo apenas para as refeições. Não haveria nenhuma atividade extraclasse. No primeiro dia de aula, me deparei com as crianças mais problemáticas da escola e não consegui realizar nenhuma atividade com elas. Com muita luta, consegui ficar com a turma até $17 \mathrm{~h}$. Decidi abandonar tudo, e assim o fiz. No dia seguinte, fui à escola somente para explicar à diretora os motivos da minha desistência e comunicar-lhe o meu desejo de assinar a minha exoneração. Voltei para casa muito aliviada. Considero essa a pior experiência que tive no magistério até hoje. (Estatutária, 34 anos, N. médio, Ciclo de Estudos 2002, memo 7).

Mais da metade das professoras, 17, falou sobre alunos, particularmente os alunos da escola pública, que são descritos como carentes, problemáticos, sem limite, agressivos, órfãos, infratores, drogados, etc. As professoras efetivas se preocupam muito mais com eles, 9 em 16, do que as contratadas, 6 em 15. Mas houve quem chamasse de ótimas as crianças da escola pública, em especial de CIEP. O que deve ser destacado aqui é o reconhecimento, por duas professoras, de que esses alunos, com todos aqueles qualificativos, podem mudar por meio da ação da escola e do professor.

Voltei para o mesmo CIEP em que fui bolsista. Retornei à sala de aula 10 anos depois, com muita dificuldade: trabalho com atividades novas (ED e vídeo); falta de recursos materiais; violência nas escolas. O que mais me impressionou foi que, assim como na minha primeira experiência, a turma que peguei em ED era uma turma muito difícil no início do ano, indisciplinada, agressiva, agitada, dispersa e, atualmente, eles já melhoraram muito nesses aspectos. Assim como na minha primeira turma de 1993, que chegou de um jeito e no final do ano era outra. Dessa forma, nós profissionais podemos perceber seu crescimento e realmente acreditar que a educação "vale a pena". (Contratada, 33 anos, $8^{\circ}$. P. pedagogia UFF, memo 20)

Foram 13 depoimentos reunidos no tema dificuldades. Novamente, predominaram os estatutários, 9, mas não os mesmos que se referiram ao aluno, essa relação não é direta. Seja como for, para os professores, o que dificulta seu trabalho cotidiano é o aluno. Dos pro- 
blemas apontados, alguns dizem respeito à escola - tamanho das turmas, falta de recurso, falta de apoio e descrença entre os professores -, mas a maioria está centrada nos alunos: na variação da faixa etária, na falta de interesse, na carência, na agressividade, na falta de apoio familiar e na dificuldade para aprender.

E o que pode ser feito para superar essas dificuldades? Com maioria entre os estatutários, 16 professores deram sugestões: a principal gira em torno de ouvir o aluno, compreender, levá-lo a participar em vez de utilizar a repressão. Pelo diálogo, ouvindo o aluno, percebe-se que ele tem conhecimento acumulado por meio da experiência, que deve ser valorizada e considerada na preparação das aulas. Dessa forma, é possível tanto resgatar a auto-estima do aluno quanto despertar seu interesse por aprender, fazê-lo gostar da escola, respeitar seus sentimentos. Uma estratégia também citada foi o envolvimento dos pais para que estimulem o aluno e este se orgulhe de sua atividade de estudante. Vejamos a ilustração:

Tive oportunidade de implementar alguns projetos relacionados ao prazer de ler e de acolhimento das famílias dos alunos, que dá grande alegria aos alunos. A valorização das relações familiares, a confraternização entre amigos desperta a parceria e o interesse pelas propostas educativas e sociais da equipe escolar. A cada ano estamos amadurecendo e aprimorando nossos objetivos em relação à melhoria da qualidade de vida de nossa comunidade. (Contratada, 40 anos, N. médio, memo 19)

Como preparar o professor para enfrentar este desafio? Essa é uma preocupação generalizada, 26 professores falaram a respeito. Classificamos seus depoimentos em três estratégias: a mais citada tem no centro a idéia de atualização, estudo, leitura, curso; aqui não há diferença entre estatutárias e contratadas. O segundo eixo fica em torno da prática: rever a prática para reorientá-la, aprender com o trabalho, aprender com o aluno, aplicar o que aprendeu e semelhantes; aqui há predomínio claro das estatutárias. E um grupo menor, sem predomínio de efetivas ou contratadas, indicou a ajuda de colegas e a integração da equipe pedagógica. Essa sugestão se distingue pelo seu caráter mais coletivo. Aqui temos um relato expressivo:

Foi no cotidiano que percebi que o curso que havia feito me deu uma base superficial e que o professor aprende a trabalhar, trabalhando... Foi uma boa experiência, quebrei muito a cabeça, precisei da ajuda das outras colegas de trabalho, mas foi muito gratificante. Nos anos seguintes... descobri como é 
bom lidar com o ser humano, não que seja fácil, mas o contato com as crianças é muito bom, faz a gente refletir como somos importantes para a coletividade. (Estatutária, 30 anos, N. médio, Ciclos de Estudo 2002 e 2003, memo 15)

Como os professores indicaram que a estratégia predominante para o desenvolvimento docente é a atualização, fomos verificar como o curso de atualização no qual estavam inscritos foi avaliado. Foram 30 depoimentos a respeito do Ciclo de Estudos, fato que não espanta, pois constava das orientações para a produção do memorial. De acordo com o que foi apontado anteriormente, a avaliação do curso deveria estar centrada, primeiramente, na atualização, e não foi isso que ocorreu: os argumentos a favor do curso se basearam na adequação à prática do professor, deixando a atualização, o estudo, a leitura em segundo plano. Em terceiro, veio a possibilidade de troca de experiência com colegas de outra ou da mesma escola. Não houve diferença entre a maneira de avaliar de estatutárias ou contratadas. A dissonância entre a estratégia para aprimoramento docente em tese e a concreta por meio da avaliação do Ciclo pode ser um indício de que a proposta abstrata esteja restrita ao discurso.

Mais uma forma de comparar a proposta em tese da execução prática a respeito do aprimoramento do professor é observar o que foi dito a respeito de cursos. Das 16 referências, 9 eram genéricas, não apontando forma, conteúdo ou nome do curso. De fato, pode-se desconsiderar esses depoimentos. Restam 7, que é muito pouco num universo de 31, cuja indicação predominante é a atualização. Foram mencionados estudos adicionais e cursos em alfabetização e leitura.

Por meio dos autores citados também podemos avaliar se a preocupação com a leitura é genérica, só para constar, ou refere-se a estudos realizados ou idéias mencionadas ao longo do memorial. Quinze professoras fizeram referência a leituras: Paulo Freire, o mais citado, aparece algumas vezes como exibição, em outras, contextualizado. A seguir, vêm Piaget e Vygotsky; no patamar seguinte, temos Ferreiro, Gadotti e Demo. Foi possível perceber que a referência consistente a autores está relacionada a curso universitário em andamento ou a um histórico de participação em cursos de atualização. A citação de Darcy Ribeiro está ligada à proposta do horário integral. Foi citada, várias vezes, a Revista Nova Escola, por ter boas orientações para a prática em sala de aula e por ter preço acessível. 


\section{CONSIDERACְÕES FINAIS}

O primeiro aspecto a destacar é a diferença entre o discurso das professoras efetivas e o das contratadas. As primeiras transmitem mais solidez, que não se confunde com coerência ou consistência teórica. Elas estão mais assentadas no real, em regras mais claras, não precisam mostrar resultado. O que se depreende do discurso das contratadas é que elas não querem se expor a situações de confronto; recorre-se ao eufemismo para exercer a crítica. É como se escrevessem o memorial considerando que ele poderia ser um instrumento de avaliação para a renovação do contrato no ano seguinte.

Não se pode afirmar que se consolidou uma representação social sobre fazer docente. O que apareceu foi a representação sobre o aluno da escola pública, em particular do CIEP. Nem todos os professores tiveram o propósito de falar do aluno e de estratégias para lidar com o aluno, aliás, pouco mais da metade; mas quando falam de escola, do professor, de estratégias para desenvolvimento do professor, todos os depoimentos estão ancorados na visão que têm do aluno. Como já foi mencionado, o professor estatutário se expõe mais ao falar do aluno carente, agressivo, com dificuldade de aprendizagem e das dificuldades que ele gera. Mas mesmo os estatutários não atribuem ao sistema de ensino os obstáculos que se impõem à prática pedagógica do professor. Culpa-se mais o aluno que o sistema de ensino.

Ao pensarem sobre as estratégias para ajudar a prática do professor - 26 professoras falaram no geral e 30, em particular, sobre o Ciclo de Estudos -, foi o aprendizado prático que predominou no grupo todo, apesar da aparente valorização de leituras, cursos e atualização. Aqui a professora está dizendo que só conta com ela mesma, ou seja, aprende trabalhando. Ela está desassistida e sem apoio. Poucas ainda se referiram à ajuda de colegas e da equipe escolar. É com o que elas contam. É um discurso da carência e não uma estratégia para conjugar forças e encontrar alternativas. Se ousarmos falar em representação do fazer docente, ela caracteriza um fazer fragilizado, individualizado, que não se consolida em visão sobre educação e sobre magistério.

Considerando que o passado é filtrado por questões e necessidades do presente, como quer Jedlowski, e este presente é tão difícil e tão frágil, como se constituiu no passado a vontade de ser professor? Os memoriais nos indicaram três caminhos para esta opção: a vocação ou motivação, da infância ou posterior, a instituição formadora e as expe- 
riências iniciais de trabalho. A vocação inicial não pareceu mais forte que a adquirida, mas ela usufrui do fato de ser o discurso vigente. Argumentar que brincava de escolinha é bastante sedutor, mas bem menos convincente de que voltar à sala de aula 10 anos depois ou de retribuir aos pais o empenho na sua formação numa família pobre, ou de abrir uma escola porque sua filha precisa estudar. As situações concretas, sejam na infância sejam posteriores, se sobrepõem como lembranças que levam à opção pelo magistério.

As instituições formadoras são lembranças significativas para a opção pelo magistério. $\mathrm{O}$ decorrer do curso, os estágios, o contato com professores formadores, a primeira entrada em sala de aula, o encantamento do contato com a criança, são todas circunstâncias que propiciam a opção pelo magistério, mesmo que não tenha sido um sonho de infância. As instituições públicas, com certeza, estimularam a opção de muitas dessas professoras. Passeggi et al. (2006, p. 262) afirmam que as lembranças das primeiras professoras e da escola apareceram como fator decisivo no perfil de professor construído em memoriais de formação. "Os ex-professores são vistos como guias, modelos, exemplos, que complementam e ampliam a representação de si e do saber ser docente".

O primeiro trabalho, em geral em escola particular, surpreendeu. Apesar das limitações das instituições privadas, que são criticadas, entre outros aspectos, por desrespeitarem as leis trabalhistas, elas configuram elemento importante da memória social de professores: lá se aprende a trabalhar, trabalhando, representação que os professores têm de como se adquire o ofício de professor. Essa recorrência à prática como processo de formação talvez revele aquela mesma decepção, constatada por Catani, dos futuros professores com os conhecimentos adquiridos em seus cursos de formação. Sua proposta de cultura da atenção estaria mais contemplada na recordação do curso de formação para professores de escola de horário integral, que ocorreu nos CIEPs no início da década de 1990. Todas as participantes que passaram pela experiência referiram-se a ela como articuladora de teoria-prática; além disso das 5 ex-bolsistas, 3 desafiaram-se a estabelecer novas formas de relação com a educação, tornando-se diretoras ou coordenadoras.

Enfim, predominou, entre as professoras, uma representação social de que a formação para a docência se alimenta de atividades práticas, que são adquiridas, de acordo com a memória socializada entre elas, por meio de práticas do passado: sejam as vivências de brincadeiras de infância ou de estágios nos cursos de formação de professores ou em 
escolas particulares; seja a convivência com modelos de professores. $\mathrm{O}$ estudo desses memoriais talvez possa ser desdobrado em análise em tantos outros municípios do estado do Rio de Janeiro, abrindo inclusive a possibilidade de comparações. Mas também poderá ser utilizado, por meio de outras aproximações, para aprofundar outras relações entre representação social e memória social. Esperamos que a contribuição oferecida aqui possa incentivar o estudo de outros memoriais propostos nas mais variadas situações.

\section{NOTAS}

${ }^{1}$ Este trabalho teve a colaboração de Lívia Paulo de Araújo, ex-orientanda no Mestrado em Educação da UNESA, tanto para resumir e quanto para tematizar os memoriais.

${ }^{2}$ Este parágrafo teve por base o Relatório de execução física das ações previstas no Projeto de Capacitação de Professores Ciclo de Estudos 2004 enviado à Secretaria de Educação do Estado do Rio de Janeiro em Janeiro de 2005 pela Fundação Darcy Ribeiro.

${ }^{3}$ Para o Curso de Atualização de Professores Bolsistas para a Escola de Horário Integral, foram selecionados professores que tinham concluído sua formação de $2^{\circ}$ grau entre 1987 e 1992. O curso, com duração de 1.600 horas, era organizado em três módulos, realizado em cada CIEP, prescrevendo que as oito horas diárias de formação se dividissem em quatro horas de prática docente orientada e quatro horas de estudos teórico-pedagógicos por meio de programas de vídeo e material impresso. Para relato do curso e sua avaliação, ver MAURíCIO et al. (1995), "Capacitação de Profissionais da Educação"; RIBEIRO, D. Carta 15: falas, reflexões, memórias; e MONTEIRO, A.M., "A formação de professores nos CIEPs: a experiência do curso de atualização de professores para escolas de horário integral no Estado do Rio de Janeiro - 1991/1994", in COELHO, L.M. e CAVALIERE, A.M. (Orgs). Educação Brasileira e (m) tempo integral.

\section{REFERÊNCIAS}

ALVES-MAZZOTTI, Alda Judith. Representações sociais: aspectos teóricos e aplicações à educação. Em Aberto, Brasília, DF, v. 14, n. 61, p. 60-78, 1994.

BARDIN, Laurence. Análise de Conteúdo. Lisboa: Edições 70, 2000.

BUENO, B. É possível reinventar os professores? A escrita de "memórias" em um curso especial de formação de professores. In: SOUZA, E; ABRAHÃO, M.H. (Org.) Tempos, narrativas e ficcões: a invenção de si. Porto Alegre: EDIPUCRS, 2006. p. 219-238.

CATANI, D. A autobiografia como saber e a educação como invenção de si. In: SOUZA, E; ABRAHÃO, M.H. (Org.) Tempos, narrativas e ficções: a invenção de si. Porto Alegre: EDIPUCRS, 2006. p. 77-87.

JEDLOWSKI, Paolo. Memória e a mídia: uma perspectiva sociológica. In: SÁ, C.P. (Org.) Imaginário e representações sociais. Rio de Janeiro: Museu da República, 2005. p. 87-98.

JODELET, Denise. Representações sociais: um domínio em expansão. In: JODELET, Denise. As representações sociais. Rio de Janeiro: EUERJ, 2001. p. 17-44.

MAURÍCIO, Lúcia Velloso et al. Capacitação dos profissionais da educação. In: Carta 15: 
o novo livro dos CIEPs. Brasília: Senado Federal, p. 183-192, 1995.

MONTEIRO, A.M. A formação de professores nos CIEPs: a experiência do curso de atualização de professores para Escolas de Horário Integral no estado do Rio de Janeiro - 1991-1994. In: COELHO, L.M.; CAVALIERE, A.M. (Org.) Educação brasileira e(m) tempo integral. Petrópolis: Vozes, 2002. p. 147-167.

PASSEGGI, M.C. A formação do formador na abordagem autobiográfica. A experiência dos memoriais de formação. In: SOUZA, E; ABRAHÃO, M.H. (Org.) Tempos, narrativas e ficções: a invenção de si. Porto Alegre: EDIPUCRS, 2006. p. 203-218.

PASSEGGI, M.C. et al. Formação e pesquisa autobiográfica. In: SOUZA, E. (Org.) Autobiografias, histórias de vida e formação: pesquisa e ensino. Porto Alegre: EDIPUCRS, 2006. p. 257-268.

ROUSSIAU, N.; BONARDI, C. Quelle place occupe la mémoire sociale dans le champ des représentations sociales? In: LAURENS, S.; ROUSSIAU, N. (Org.) La mémoire sociale: identités et représentations sociales. Rennes: Presses Universitaires de Rennes, 2002. p. 33-49.

SÁ, Celso P. As memórias da memória social. In: SÁ, C.P. (Org.) Memória, imaginário e representações sociais. Rio de Janeiro: Museu da República Editora, 2005. p. 63-86.

VALENCIA, Jose Francisco. Representações e memória social: vicissitudes de um objeto em busca de uma teoria. In: SÁ, C.P. (Org.). Memória, imaginário e representações sociais. Rio de Janeiro: Museu da República Editora, 2005. p. 99-119.

Recebido: $28 / 05 / 07$

Aprovado: 24/07/08

Contato:

Rua Paissandu 228 / apto 305

Flamengo

Rio de Janeiro - RJ

$22.10-080$ 